\title{
In vitro susceptibility of bovine mastitis pathogens to a combination of penicillin and framycetin: Development of interpretive criteria for testing by broth microdilution and disk diffusion
}

\author{
C. M. Pillar, ${ }^{* 1}$ A. Stoneburner, ${ }^{*}$ D. L. Shinabarger, ${ }^{*}$ E. Abbeloos, $\dagger$ and L. Goby $\dagger$ \\ *Micromyx LLC, Kalamazoo, MI 49008 \\ †Boehringer-Ingelheim, 55216 Ingelheim am Rhein, Germany
}

\begin{abstract}
Dry cow therapy is an important part of mastitis control. This therapy typically consists of an antibiotic or antibiotics administered at a single dose by intramammary infusion at dry off to treat or prevent infection by prevalent mastitis pathogens. A combination dry cow therapy consisting of the active components penicillin and framycetin is currently used in several countries. Despite its use, standardized methods for the susceptibility testing of this combination against mastitis pathogens have not been established. In this study, which used Clinical and Laboratory Standards Institute methodology, preliminary interpretive criteria for the broth microdilution minimum inhibitory concentration (MIC) testing of mastitis pathogens to penicillin combined with framycetin $(2: 1 \mathrm{wt} / \mathrm{wt})$ were established based on the amount of drug achieved and maintained postadministration in the udder. Based on resulting MIC distributions of recent veterinary field isolates and a subset of isolates preselected for resistance to $\beta$-lactams or aminoglycosides and concentrations achieved postadministration, criteria for broth microdilution testing of the combination (susceptible, intermediate, resistant in micrograms per milliliter) were set as follows: Escherichia coli $\leq 8 / 4,16 / 8, \geq 32 / 16$; Staphylococcus spp. $\leq 2 / 1,4 / 2-8 / 4,>16 / 8 ;$ Streptococcus uberis and Streptococcus dysgalactiae $<0.25 / 0.12$, $0.5 / 0.25-2 / 1,>4 / 2$. A disk diffusion test using disks containing $100 \mu \mathrm{g}$ of framycetin and $10 \mathrm{IU}$ of penicillin was also developed, and preliminary interpretive criteria (susceptible, intermediate, resistant in millimeters) were set based on correlation to broth MIC values and the minimization of interpretive errors between isolates tested concurrently by broth microdilution and disk diffusion as follows: E. coli $\geq 18,16-17, \leq 15$; Staphylococcus spp. $\geq 21,18-20, \leq 17$; Strep. uberis and Strep. dysgalactiae $\geq 21,19-20, \leq 18$. In addition, ranges for
\end{abstract}

Received February 6, 2014.

Accepted June 25, 2014

${ }^{1}$ Corresponding author: cpillar@micromyx.com the quality control of the testing of this combination by both broth microdilution and disk diffusion are provided. Based on these criteria and recent veterinary mastitis isolates, $96.0 / 96.8 \%$ of E. coli, $93.7 / 89.1 \%$ of Staph. aureus, 94.6/96.4\% coagulase-negative staphylococci, 94.5/97.0\% of Strep. uberis, and 96.7/100.0\% Strep. dysgalactiae were susceptible to the combination by broth microdilution or disk diffusion, respectively. The availability of these methods will allow for the susceptibility testing of clinical isolates in the field and will also provide a way to monitor for resistance development as this combination is used going forward.

Key words: mastitis, dry cow therapy, sensitivity testing, susceptibility testing, antibiogram

\section{INTRODUCTION}

Strategies for preventing or treating bovine mastitis, an inflammation of the mammary gland of dairy cattle typically caused by bacteria, vary widely but typically involve the use of antibiotics. Treatment of cows at drying off with an infusion of antibiotics, alone or in combination, is a common part of mastitis infection control programs throughout the world (Hogeveen et al., 2011). The widespread use of dry cow therapy (DCT) can be largely attributed to studies that have shown a significant prophylactic benefit and curative properties of DCT with respect to mastitis (Smith et al., 1967; Bradley and Green, 2001; Berry and Hillerton, 2002) and its cost effectiveness (Berry et al., 2004). In addition, the prevention and treatment of mastitis, a painful infection even in its mildest forms, is consistent with the standards set for animal welfare in most developed nations (Fitzpatrick et al., 1998).

Though the etiology of bovine mastitis can be diverse and can vary regionally (Watts, 1988), Staphylococcus aureus, CNS, streptococci (primarily Streptococcus uberis and Streptococcus dysgalactiae), enterococci, and coliforms (primarily Escherichia coli) comprise the majority of bacterial species isolated from dairy cattle with either infectious or environmental mastitis. Historically, the majority of cases of bovine mastitis were caused by 
infectious pathogens (e.g., Staph. aureus, Streptococcus agalactiae; Hillerton and Berry, 2005). However, the use of antibiotic intervention, improved herd management, and other control measures has greatly curtailed the frequency of infectious mastitis among herds (Bradley, 2002; Hillerton and Berry, 2005). In contrast, the prevalence of environmental mastitis typically caused by Strep. uberis and coliforms (e.g., E. coli) has increased. Also, CNS seem to be emerging, although their clinical relevance is still unclear (Pyörälä and Taponen, 2009). Mastitis infections during the dry period result either from carryover of subclinical mastitis established before drying off or as new infections that initiate during the prolonged dry period (Bradley and Green, 2004). Over $50 \%$ of environmental clinical mastitis cases observed in early lactation originate during the dry period (Bradley and Green, 2004). Thus, an effective DCT is active against common mastitis pathogens over an extended period of time, resulting in the elimination of latent infection at dry off, prevention of infection during the dry period, and, as a result, reducing the risk of clinical mastitis during the subsequent lactation.

Antibiotics, when used in combination, broaden the coverage of target pathogens observed with either agent alone. Most DCT effectively target the elimination of infections present at dry off caused by gram-positive bacteria and the prevention of new infections by grampositive pathogens, mainly Staph. aureus and Strep. uberis, during the early dry-off period (National Mastitis Council, 2006). In addition, given the increased incidence rates of environmental mastitis and that usually 20 to $30 \%$ of clinical mastitis is ultimately caused by gram-negative organisms (Bradley, 2002; Bradley and Green, 2009; Ericsson Unnerstad et al., 2009), it is important to cover infection with gram-negative organisms such as E. coli and to provide prolonged coverage against mastitis pathogens throughout the dry period. Most DCT is administered as a single-use intramammary infusion at dry off, and the duration of activity across available DCT varies. Given the need for prolonged activity due to the length of the dry-off period, most DCT consists of high doses of the active agents in a matrix that prolongs their activity, or contains antibiotics which have demonstrated increased stability over time and low rates of elimination (National Mastitis Council, 2006).

Ubrostar (Boehringer Ingelheim, Ingelheim, Germany) is marketed as a DCT in several countries throughout Europe, South America, and the Middle East as a single-use intramammary infusion containing a combination of penethamate hydriodide (100,000 IU), benethamine penicillin (280,000 IU), and framycetin sulfate (100 mg; Boehringer Ingelheim 2013). Penicillin and framycetin concentrations present in dry udder secretions postadministration are shown in Figure 1 (E. Abbeloos, Boehringer Ingelheim, data on file). Penicillin is delivered at 380,000 IU from the penethamate hydriodide and benethamine penicillin combined. The penethamate rapidly penetrates udder tissue relative to other penicillins (benzylpenicillin, cloxacillin, dicloxacillin; Ziv, 1980; Friton et al., 2003) and has exhibited activity against mastitis pathogens internalized within mammary epithelial cells (Almeida et al., 2007), allowing for effective coverage of staphylococci and streptococci at dry off and during the early dry-off period (Figure 1). Framycetin is delivered at $100 \mathrm{mg}$ and binds to udder tissue remaining at high levels for up to $14 \mathrm{wk}$ (Figure 1), covering gram-negative species and staphylococci, including those resistant to penicillin, for the duration of the dry period. Importantly, despite its ability to persist in the udder during the dry period, framycetin is rapidly eliminated from the udder once lactation begins (EMEA, 2002). This combination has demonstrated good efficacy as a DCT in several controlled field trials (Osterås et al., 1994; Osterås and Sandvik, 1996; Bradley and Green, 2001).

Prudent use guidelines for antibiotics dictate that when considering antimicrobial chemotherapy, the antibiotic used must represent the most suitable antibacterial for the indicated use, that administration must closely adhere to the instructions provided in the label, and that the use of antibiotics of last resort should be restricted (Ungemach et al., 2006). Due to increasing antimicrobial resistance, the prophylactic use of antibiotics among animals is a topic of debate and highlights the need for simple and easy to use methods for susceptibility testing to better guide veterinarians

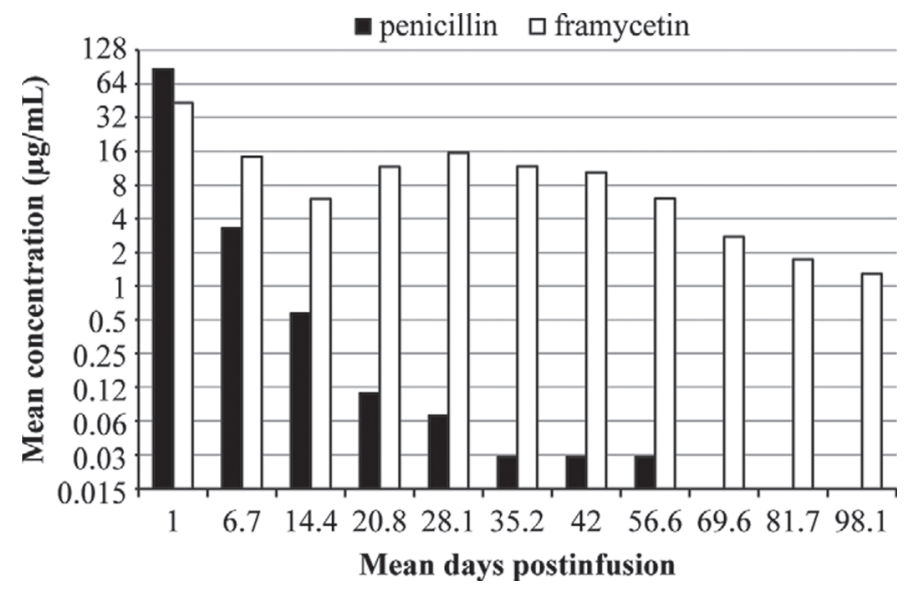

Figure 1. Detection of framycetin and penicillin residues in the dry udder secretions of cows after intramammary administration of Ubrostar (100 mg of penethamate hydriodide, $180 \mathrm{mg}$ of benethamine penicillin, $100 \mathrm{mg}$ of framycetin sulfate). Results represent the mean detected from samples from each quarter of 10 to 15 cows d 1 to 56.6, and 4 to 10 cows d 69.6 to 98.1 . 
when selecting treatments for infected or at risk animals so that an appropriate choice is made. Despite the widespread use of this combination as DCT, no standard in vitro methods have been developed to evaluate the susceptibility of bovine mastitis pathogens to the combination of penicillin and framycetin directly, and no interpretive criteria exists for framycetin as a single agent. In general, when developing test methods and setting interpretive criteria it is important to take into consideration the pharmacokinetics/pharmacodynamics $(\mathbf{P K} / \mathbf{P D})$ of the test agent(s), the correlation of in vitro data with clinical outcome, and the in vitro activity against a large representative population of target pathogens, as well as pathogens with known resistant profiles (CLSI, 2009a). Defining in vitro interpretive criteria that are clinically predictive in the context of mastitis proves difficult because antibiotics are commonly administered directly into the udder, a complex space not amenable to traditional $\mathrm{PK} / \mathrm{PD}$ analysis or Monte Carlo simulation. In addition, in the context of a prophylactic DCT, clinically predictive breakpoints are difficult to derive, as susceptibility data gathered in this context is largely limited to samples taken at dry off and the organisms present at dry off may or may not be the etiologic agents of IMI observed during the subsequent dry period.

Given these caveats, the test methods and interpretive criteria as described herein were developed based on several factors, including the concentration of active residues of penicillin and framycetin in the udder after administration, resulting MIC distributions against recent field isolates of target bovine mastitis pathogens, and MIC values against isolates with preselected resistance to $\beta$-lactams or aminoglycosides. As such, interpretive criteria were set to fit the normal MIC distribution observed among veterinary isolates and the concentrations able to be achieved in the udder. These criteria were designed to characterize isolates as susceptible if the isolate has an MIC for either agent lower than the concentrations achieved postadministration and as resistant if the MIC for both agents exceeds the concentrations achieved postadministration.

A disk test and interpretive criteria for disk diffusion testing were established based on correlation to broth microdilution susceptibility testing results. The resulting interpretive criteria established for the broth microdilution testing of penicillin:framycetin and disk diffusion testing are thus relevant in the context of DCT and provide a simple controlled test for the evaluation the susceptibility of mastitis field isolates to this combination, either by disk diffusion or broth microdilution. These methods enable surveillance for resistance development to the combination going forward.

\section{MATERIALS AND METHODS}

\section{Bacterial Isolates}

Veterinary field bovine mastitis isolates were supplied by Quality Milk Management (Cheddar, UK) and human clinical isolates selected for resistance phenotype were supplied by Micromyx (Kalamazoo, MI). Veterinary field isolates consisted of 112 Staph. aureus, 106 CNS, 97 Strep. uberis, 2 Strep. parauberis, 30 Strep. dysgalactiae, and 110 E. coli isolated from 12 sites distributed across 6 European countries from 2011 to 2012. The isolates came from clinical and subclinical cases of mastitis throughout various stages of lactation. All veterinary isolates were identified by matrix-assisted laser desorption/ionization-time of flight (MALDI-TOF; Bruker, Billerica, MA). These random, nonduplicate field isolates were used to establish the current veterinary antibiogram for the combination and comparators against mastitis isolates. Human clinical isolates consisted of 16 Staph. aureus, 5 Staphylococcus epidermidis, and 14 E. coli. Human isolates were selected for relevant $\beta$-lactam and aminoglycoside phenotype based on prior testing regardless of specimen type. Human isolates and veterinary isolates were evaluated together to establish the interpretive criteria based on overall MIC distribution and to set interpretive breakpoints for disk diffusion by broth versus disk correlation and error-rate bounding analysis (CLSI, 2009a). Overall, 128 Staph. aureus, 111 CNS, 99 Strep. uberis or Strep. parauberis, 30 Strep. dysgalactiae, and 124 E. coli were evaluated in the current study.

\section{Determination of Framycetin and Penicillin G Concentrations in Dry Udder Secretions Postadministration}

Concentrations of framycetin and penicillin $G$ from dry udder secretions were measured over a 14 -wk period after administration of Ubrostar [penethamate hydriodide (100,000 IU), benethamine penicillin (280,000 IU), and framycetin sulfate $(100 \mathrm{mg})$; Boehringer Ingelheim] in a study conducted previously by the manufacturer (E. Abbeloos, Boehringer Ingelheim, data on file). In accordance with the Summary of Product Characteristics (Boehringer Ingelheim, 2013), a single intramammary dose of Ubrostar was administered per quarter to 15 dairy cattle. Dry udder secretions were collected as available for analysis at $\mathrm{d} 1$ postadministration and approximately every week after for a 6 -wk period, followed by collection of samples approximately every 2 wk for the remainder of the study through wk 14 . From d 1 through wk 8, secretions were collected from each quarter of between 10 and 15 animals. From wk 
8 through 14, secretions were collected from between 4 and 9 animals. Each sample was weighed and stored at $-20^{\circ} \mathrm{C}$ before the assay. Concentrations of penicillin $\mathrm{G}$ and framycetin in samples were determined in triplicate based on the observed in vitro activity against Bacillus subtilis NCTC 10400 relative to standard curves generated from penicillin $(0.5-8 \mathrm{mg} / \mathrm{L})$ and framycetin (2.5-40 $\mathrm{mg} / \mathrm{L})$ suspended in milk. Viscous samples were sonicated using Dawes Soniprobe (London, UK) before evaluation. Assays for penicillin activity were conducted using disks impregnated with standards or test samples, by applying the disks to Penassay Seed Agar (Difco, Becton Dickinson, Franklin Lakes, NJ) containing B. subtilis, and by measuring resulting zones of growth inhibition after incubation. Assays for framycetin activity were conducted by applying samples to 10.5-mm agar wells in Diagnostic Sensitivity Test Agar (Oxoid, Basingstoke, UK) containing $B$. subtilis and measuring the resulting growth inhibition after incubation. Samples giving results greater than the highest standard concentration tested for each agent were subsequently diluted and retested. Samples giving results smaller than the lowest concentration of standard tested were retested alongside standards at a lower concentration range $(0.03-0.5$ and $0.5-8 \mathrm{mg} / \mathrm{L}$ for penicillin and framycetin, respectively). Data were ultimately presented as the mean concentration of framycetin or penicillin in positive quarters in micrograms per milliliter.

\section{Susceptibility Testing by Broth Microdilution and Disk Diffusion}

Susceptibility of isolates to penicillin, framycetin, penicillin and framycetin at a 2:1 wt/wt fixed ratio, and kanamycin (used to provide some assessment of aminoglycoside susceptibility due to the absence of established framycetin interpretive criteria) was determined by broth microdilution in accordance with Clinical and Laboratory Standards Institute guidelines (CLSI, 2009b). Of note, interpretive criteria for kanamycin and penicillin are based on human PK/PD and correlation to clinical outcome in humans, not animals (CLSI 2009b). Broth microdilution test panels were made in-house at Micromyx. Serial 2-fold dilution series of $20 \times$ drug stocks of penicillin (Sigma-Aldrich, St. Louis, MO), framycetin (Discovery Fine Chemicals, Bournemouth, UK), and kanamycin (Sigma-Aldrich) in the recommended solvent or diluent (CLSI, 2009a,b) were prepared using the Biomek 2000 (Beckman Coulter, Fullerton, CA). A $5-\mu \mathrm{L}$ aliquot of each drug at $20 \times$ the final test concentration was transferred to a Costar 3795 96-well plate (Corning Inc., Corning,
NY) prefilled with $85 \mu \mathrm{L}$ of cation-adjusted MuellerHinton broth in a single step using the Biomek F/X (Beckman Coulter) in cation-adjusted Mueller-Hinton broth (Becton Dickinson, Franklin Lakes, NJ). Cationadjusted Mueller-Hinton broth was supplemented with $2 \%$ lysed horse blood (Cleveland Scientific, Bath, $\mathrm{OH}$ ) for the testing of streptococci. Panels were stored at $-80^{\circ} \mathrm{C}$ before inoculation. Frozen stocks of the isolates were thawed and subcultured on tryptic soy agar plates containing $5 \%$ sheep blood (Remel, Lenexa, KS). Panels were inoculated with $10 \mu \mathrm{L}$ of a 1:10 diluted $0.5-\mathrm{McF}$ arland suspension of test isolate, resulting in a final concentration of approximately $5 \times 10^{5} \mathrm{cfu} /$ $\mathrm{mL}$ in each test well. Panels were incubated at $35^{\circ} \mathrm{C}$ in ambient air, and the MIC was determined after 18 to $24 \mathrm{~h}$. Susceptibility of isolates to the combination was further analyzed based on susceptibility to penicillin or kanamycin, as applicable (CLSI, 2009b). Framycetin susceptibility was determined based on the apparent epidemiological cutoff (ECOFF) as observed visually with the tested isolates (based on the concentration at the end of the normal distribution and the separation of the apparent susceptible population from any apparent resistant population, if any). The susceptibility of the test isolates was also evaluated by disk diffusion in accordance with Clinical and Laboratory Standards Institute guidelines (CLSI, 2009b) using commercially manufactured disks containing penicillin G (10 IU; Oxoid) kanamycin (30 $\mu \mathrm{g}$; Oxoid), framycetin (100 $\mu \mathrm{g}$; Oxoid), and $10 \mathrm{IU}$ of penicillin G combined with $100 \mu \mathrm{g}$ of framycetin (Mast Diagnostics, Merseyside, UK). Due to limited availability, framycetin disks made in house at Micromyx were used for a portion of the testing after establishing equivalency to commercially manufactured framycetin disks. In brief, framycetin disks were made by spotting $13.6 \mu \mathrm{L}$ of drug stock at the appropriate concentration onto sterile Whatman paper disks (Riviera Beach, CA) and were allowed to dry in a biological hood. The disk content of the combination disk tested in our study was established after the evaluation of 5 disks with varied amounts of penicillin and framycetin (data not shown) based on its overall correlation with broth MIC values and the generation of optimum disk zones presumed to be susceptible or resistant to the combination (CLSI, 2009a). Using the same 0.5-McFarland inoculum suspension for each test isolate used in broth microdilution testing as described previously, the surface of a Mueller-Hinton agar plate (Remel), or in the case of streptococci Mueller-Hinton agar supplemented with $5 \%$ sheep blood (Remel), was inoculated with a sterile swab. After the inoculum had dried, the disks were applied to the surface of the plate. After incubation at $35^{\circ} \mathrm{C}$ in ambient air for staphylococci and 
Table 1. Recommended interpretive criteria for the susceptibility testing of penicillin in combination with framycetin against bovine mastitis pathogens by broth microdilution (pen:fram 2:1 wt/wt fixed ratio) and disk diffusion (100 $\mu \mathrm{g}$ of framycetin/10 IU of penicillin G)

\begin{tabular}{|c|c|c|c|c|c|c|}
\hline \multirow[b]{2}{*}{ Organism } & \multicolumn{3}{|c|}{ Broth microdilution $(\mu \mathrm{g} / \mathrm{mL})$} & \multicolumn{3}{|c|}{ Disk diffusion (mm) } \\
\hline & Susceptible & Intermediate & Resistant & Susceptible & Intermediate & Resistant \\
\hline Staphylococcus spp. & $\overline{<} 2 / 1$ & $4 / 2-8 / 4$ & $>16 / 8$ & $\overline{>} 21$ & $18-20$ & $\overline{<} 17$ \\
\hline Streptococcus uberis and Streptococcus dysgalactiae & $\leq 0.25 / 0.12$ & $0.5 / 0.25-2 / 1$ & $\geq 4 / 2$ & $\geq 21$ & $19-20$ & $\leq 18$ \\
\hline
\end{tabular}

E. coli for a period of 16 to $28 \mathrm{~h}$ and $35^{\circ} \mathrm{C}$ in $5 \% \mathrm{CO}_{2}$ for streptococci for a period of $24 \mathrm{~h}$, the zone of inhibition were measured.

\section{Evaluation of Interpretive Criteria for Broth Microdilution and Disk Diffusion Testing}

Breakpoints for the broth microdilution testing of penicillin in combination with framycetin at a fixed ratio of 2:1 wt/wt were selected based on the overall MIC distribution and the concentration achieved in the udder during the dry period. Based on these breakpoints, error-rate bounding analysis of preliminary interpretive criteria for disk diffusion testing of the combination was conducted in accordance with Clinical and Laboratory Standards Institute (CLSI, 2009a), and consisted of determining whether minor error rates (calling a susceptible or resistant isolate intermediate by disk or calling an intermediate isolate susceptible or resistant by disk), major error rates (false resistant by disk), and very major error rates (false susceptible by disk) are within acceptable limits.

\section{Quality Control}

Preliminary tier 1 quality control ranges for the testing of the combination by broth microdilution and disk diffusion were established by testing a total of 10 multiple independent inocula of American Type Culture Collection (ATCC) quality control (QC) isolates, as described herein, across 3 separate lots of media (CLSI, 2009a). Staphylococcus aureus ATCC 29213 (broth microdilution), Staph. aureus ATCC 25923 (disk diffusion), E. coli ATCC 25922, and Streptococcus pneumoniae ATCC 49619 (broth microdilution and disk diffusion) were tested for purposes of quality control throughout the study as directed by the Clinical and Laboratory Standards Institute (CLSI, 2009b).

\section{RESULTS AND DISCUSSION}

Preliminary interpretive criteria for broth microdilution and disk diffusion testing of penicillin in combi- nation with framycetin based on the data presented below are shown in Table 1. Interpretive criteria are typically established based on correlation of MIC to clinical outcome, PK/PD analysis, and MIC distribution (CLSI, 2009a). However, in the context of a DCT for the prevention of mastitis, correlation of MIC to clinical outcome and traditional PK/PD analysis is not possible. In lieu of this data, the interpretive criteria presented herein are based on the MIC distribution of the combination against recent veterinary field isolates and select resistant isolates, or ECOFF, taking into account the pharmacokinetics of the active agents of the combination postadministration in the udder (Figure 1). Though not clinically predictive, these criteria are useful for evaluating the activity of the combination against field isolates and to monitor for the emergence of resistance to the combination over time.

For the data presented herein, broth microdilution testing of penicillin and framycetin in combination was conducted at a fixed ratio of $2: 1 \mathrm{wt} / \mathrm{wt}$ penicillin:framycetin, which represents the relative ratio of these agents $48 \mathrm{~h}$ after administration in the udder of dairy cows (E. Abbeloos, Boehringer Ingelheim, data on file). This ratio was chosen because the relative concentration of the agents during early dry off is critical for the elimination of any mastitis causing pathogens and treatment of mastitis carried over before the dry period. Disk diffusion for the combination was conducted with disks containing $10 \mathrm{IU}$ of penicillin and $100 \mu \mathrm{g}$ of framycetin, which was determined to correlate with broth microdilution MIC values, as shown herein, and represents the disk content commonly used for the testing of these agents individually. The antibiogram for penicillin and framycetin by broth microdilution testing alongside penicillin, framycetin, and kanamycin tested as single agents against bovine mastitis isolates is shown in Table 2. Framycetin results were interpreted based on the ECOFF, as observed in the current study, and kanamycin was tested to evaluate susceptibility to aminoglycosides, as clinical breakpoints for kanamycin have been established for the evaluated staphylococci and E. coli (CLSI 2009b). It is important to note that variation in susceptibility exists among members of the aminoglycosides. 
OUR INDUSTRY TODAY

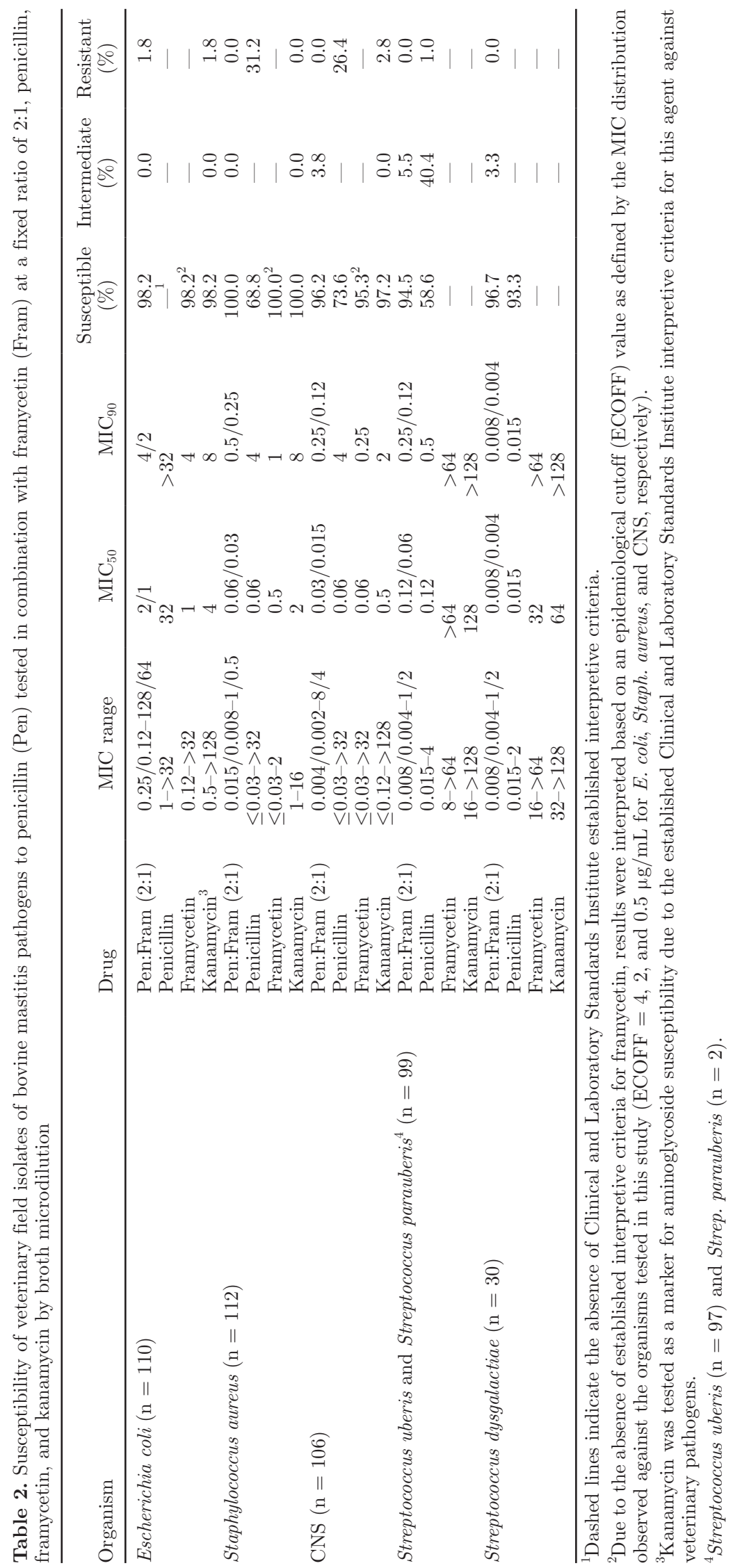



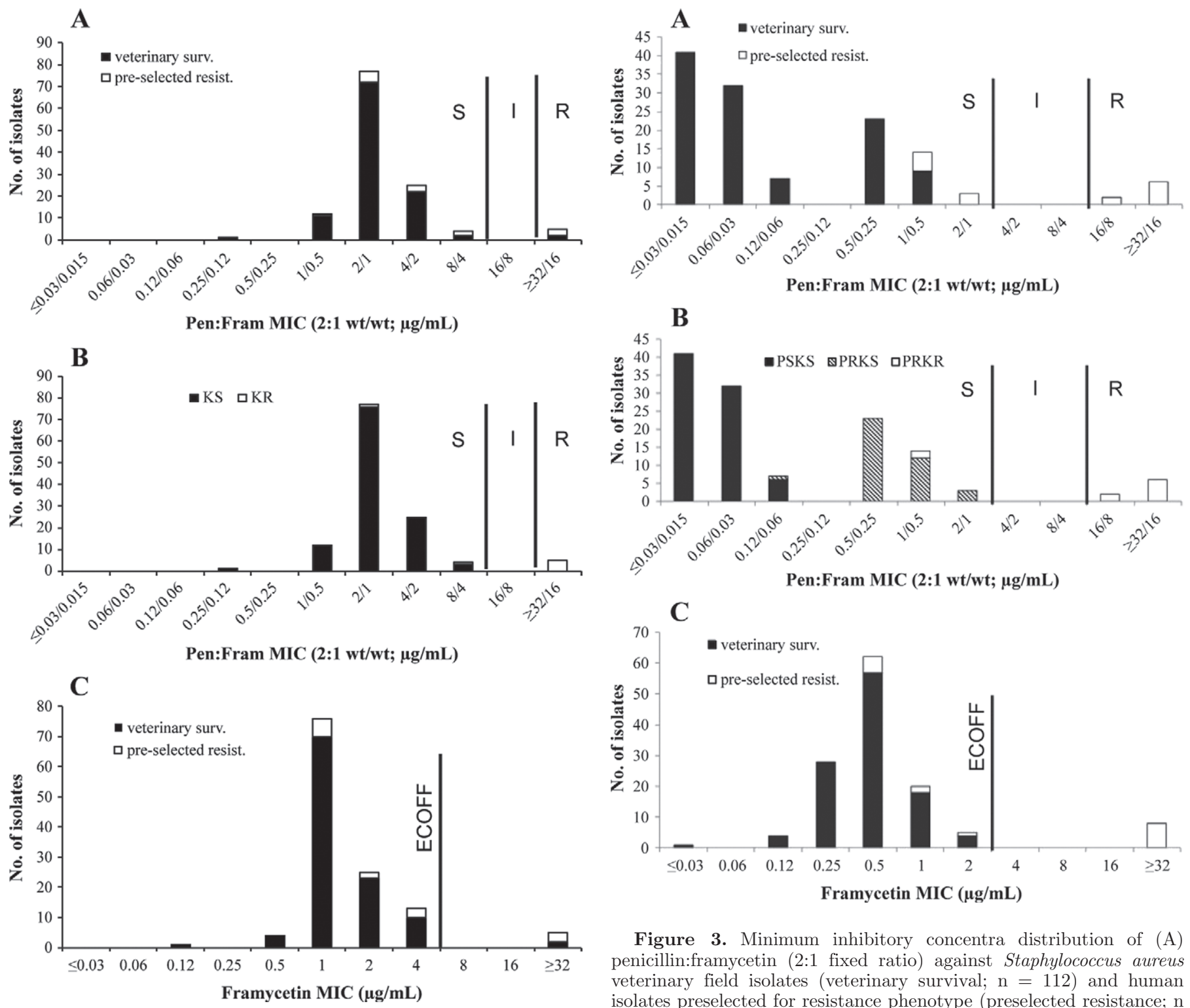

Figure 2. Minimum inhibitory concentration distribution of $(\mathrm{A})$ penicillin:framycetin (2:1 fixed ratio) against Escherichia coli veterinary field isolates (veterinary survival; $\mathrm{n}=110$ ) and human isolates preselected for resistance phenotype (preselected resistance; $\mathrm{n}=14$ ); (B) penicillin:framycetin (2:1 fixed ratio) against kanamycin-susceptible $(\mathrm{KS} ; \mathrm{n}=117)$ and kanamycin-resistant $(\mathrm{KR} ; \mathrm{n}=7) E$. coli; and (C) framycetin against $E$. coli overall $(\mathrm{n}=124)$. $\mathrm{S}=$ susceptible; $\mathrm{I}=$ intermediate; $\mathrm{R}=$ resistant; $\mathrm{ECOFF}=$ epidemiological cut-off.

The MIC distribution of E. coli overall and by kanamycin-resistance phenotype is shown in Figure 2 A-B. Based on broth microdilution MIC values, the evaluated veterinary isolates were highly susceptible to aminoglycosides, with only $1.8 \%$ of isolates testing as kanamycin-resistant (Table 2). Using an ECOFF of $4 \mu \mathrm{g} / \mathrm{mL}$ for framycetin as determined by the overall MIC distribution (Figure 2C), 98.2\% of isolates were determined to be framycetin-susceptible. The levels of

Figure 3. Minimum inhibitory concentra distribution of (A) penicillin:framycetin (2:1 fixed ratio) against Staphylococcus aureus veterinary field isolates (veterinary survival; $\mathrm{n}=112$ ) and human isolates preselected for resistance phenotype (preselected resistance; $\mathrm{n}$ $=16)$; (B) penicillin:framycetin (2:1 fixed ratio) against penicillin- and kanamycin-susceptible (PSKS; $\mathrm{n}=79$ ), penicillin-resistant and kanamycin-susceptible (PRKS; $\mathrm{n}=39$ ), and penicillin- and kanamycinresistant (PRKR; $\mathrm{n}=10)]$ Staph. aureus; and (C) framycetin against Staph. aureus overall $(\mathrm{n}=128) . \mathrm{S}=$ susceptible; $\mathrm{I}=$ intermediate; $\mathrm{R}$ $=$ resistant; $\mathrm{ECOFF}=$ epidemiological cut-off.

aminoglycoside susceptibility observed with veterinary isolates of $E$. coli is consistent with that observed in other veterinary surveillance studies (Erskine et al., 2002; Lehtolainen et al., 2003; Makovec and Ruegg, 2003; Wallmann et al., 2003; White, 2006; Pillar et al., 2009). As expected, penicillin had little to no activity alone against $E$. coli. Using the preliminary interpretive criteria shown in Table 1, $98.2 \%$ of veterinary isolates were susceptible to the combination and $1.2 \%$ were resistant with an $\mathrm{MIC}_{50}$ of $2 / 1 \mu \mathrm{g} / \mathrm{mL}$ and an $\mathrm{MIC}_{90}$ of $4 / 2 \mu \mathrm{g} / \mathrm{mL}$. For the 2 resistant isolates, both had MIC 

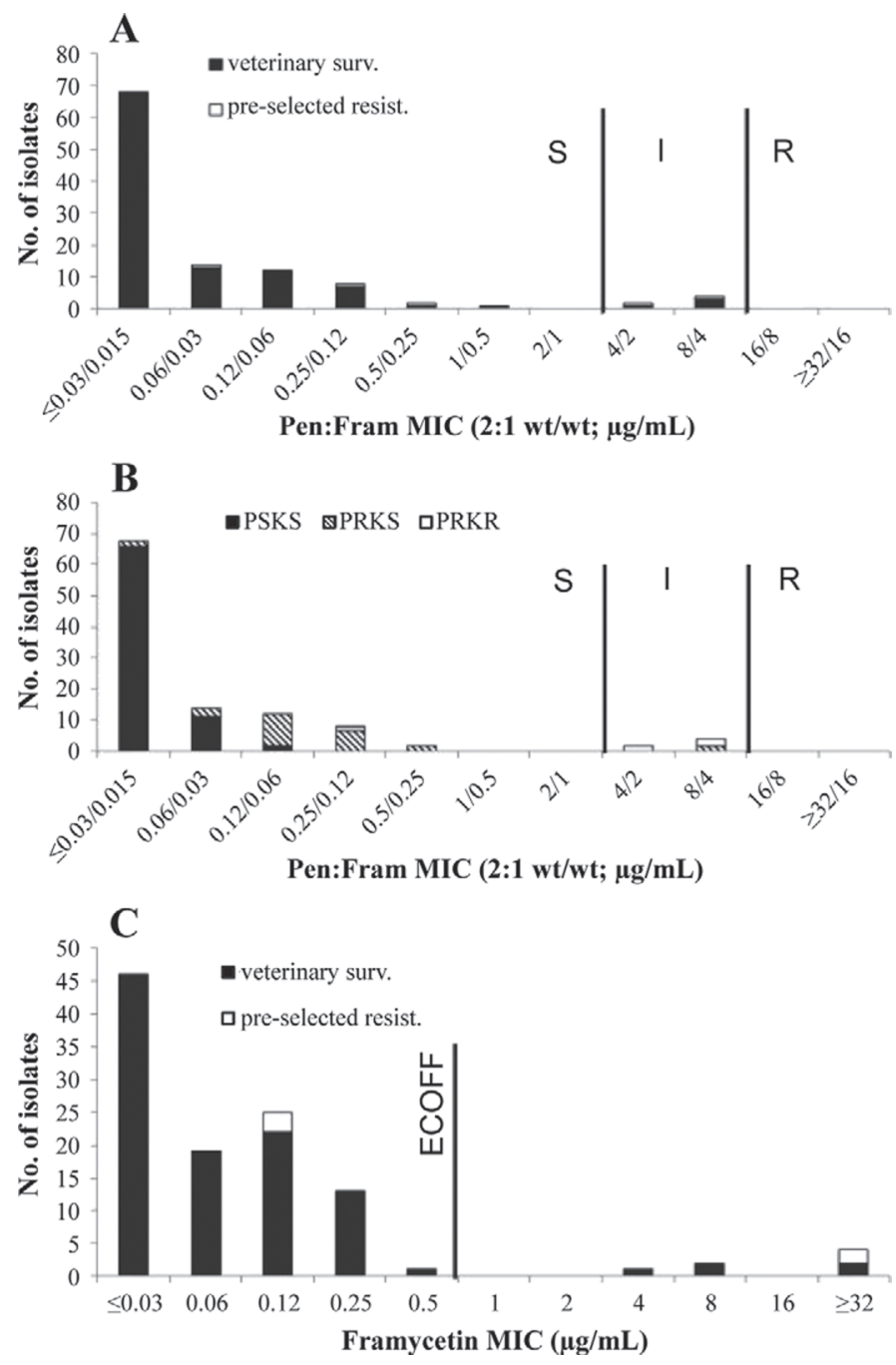

Figure 4. Minimum inhibitory concentration distribution of (A) penicillin:framycetin (2:1 fixed ratio) against CNS veterinary field isolates (veterinary survival; $\mathrm{n}=106$ ) and human isolates preselected for resistance phenotype (preselected resistance; $\mathrm{n}=5$ ); $(\mathrm{B})$ penicillin:framycetin (2:1 fixed ratio) against penicillin- and kanamycin-susceptible (PSKS; $\mathrm{n}=79$ ), penicillin-resistant and kanamycinsusceptible (PRKS; $\mathrm{n}=26$ ), and penicillin- and kanamycin-resistant $($ PRKR; $\mathrm{n}=6) \mathrm{CNS}$; and $(\mathrm{C})$ framycetin against CNS overall $(\mathrm{n}=$ 111). $\mathrm{S}=$ susceptible, $\mathrm{I}=$ intermediate, $\mathrm{R}=$ resistant, $\mathrm{ECOFF}=$ epidemiological cut-off.

values of $>32 \mu \mathrm{g} / \mathrm{mL}$ for framycetin alone and an MIC of $128 / 64 \mu \mathrm{g} / \mathrm{mL}$ for the combination.

The MIC distribution by phenotype (Figure 2B) shows that, in addition to the 2 kanamycin-resistant isolates, 5 of the 14 human clinical isolates of $E$. coli preselected based on aminoglycoside resistance were kanamycin-resistant. Three of these had framycetin MIC values $\geq 32 \mu \mathrm{g} / \mathrm{mL}$ and were thus resistant to the combination with MIC values of $\geq 128 / 64 \mu \mathrm{g} / \mathrm{mL}$. The remaining 2 kanamycin-resistant isolates had framycetin MIC values of 1 to $4 \mu \mathrm{g} / \mathrm{mL}$, and as a result were susceptible to the combination with MIC values of $8 / 4$ and $2 / 1 \mu \mathrm{g} / \mathrm{mL}$.

The preliminary interpretive criteria set for broth microdilution testing of the combination against $E$. coli fit the MIC distribution dividing the normally distributed wild-type population $(1 / 0.5-8 / 4 \mu \mathrm{g} / \mathrm{mL})$ from the resistant population with MIC values $\geq 128 / 64 \mu \mathrm{g} /$ $\mathrm{mL}$ (Figure $2 \mathrm{~A}-\mathrm{B}$ ). The results reflect the concentration of framycetin in the udder, which is detectable at $>4 \mu \mathrm{g} / \mathrm{mL}$ for 8 wk after administration (Figure 1 ).

The MIC distribution of Staph. aureus and CNS overall and by penicillin- or kanamycin-resistance phenotype is shown in Figures $3 \mathrm{~A}-\mathrm{B}$ and $4 \mathrm{~A}-\mathrm{B}$, respectively. Based on broth microdilution MIC values, the evaluated veterinary isolates were highly susceptible to aminoglycosides, with only $2.8 \%$ of Staph. aureus isolates testing as kanamycin-resistant and no kanamycin resistance among CNS (Table 2). Using an ECOFF of $2 \mu \mathrm{g} / \mathrm{mL}$ for framycetin, as determined by the overall MIC distribution (Figures 3C and 4C), 95.3\% of CNS and $100 \%$ of Staph. aureus veterinary isolates were determined to be framycetin-susceptible. The high degree of susceptibility of staphylococci to aminoglycosides observed with mastitis isolates was consistent with other veterinary surveillance studies (Gentilini et al., 2000; Erskine et al., 2002; Makovec and Ruegg, 2003; Aarestrup and Schwarz, 2006; Pillar et al., 2009; Silley et al., 2012). In contrast, penicillin resistance among these isolates ranged from $26.4 \%$ with CNS to $31.2 \%$ with Staph. aureus. The level of penicillin resistance varies considerably based on geography, but, as observed in the current study, a significant degree of penicillin resistance has been reported previously for both Staph. aureus and CNS (Pitkälä et al., 2004; Hendriksen et al., 2008; Persson et al., 2011; El Behiry et al., 2012; Oliveira et al., 2012). The susceptibility of veterinary isolates to cloxacillin was also evaluated and only $1.8 \%$ of Staph. aureus and 5.6\% of CNS had cloxacillin MIC values $\geq 4 \mu \mathrm{g} / \mathrm{mL}$, indicating a low rate of methicillin resistance among these isolates (data not shown). Using the preliminary interpretive criteria shown in Table 1, $100 \%$ of veterinary isolates of Staph. aureus and $96.2 \%$ of CNS were susceptible to the combination with no detected resistance. An $\mathrm{MIC}_{50}$ of $0.06 / 0.03 \mu \mathrm{g} / \mathrm{mL}$ and $\mathrm{MIC}_{90}$ of $0.5 / 0.25 \mu \mathrm{g} / \mathrm{mL}$ was observed for the combination against Staph. aureus veterinary isolates and an $\mathrm{MIC}_{50}$ of $0.03 / 0.015 \mu \mathrm{g} / \mathrm{mL}$ and $\mathrm{MIC}_{90}$ of $0.25 / 0.12$ $\mu \mathrm{g} / \mathrm{mL}$ was observed for the combination against CNS isolates.

The MIC distribution of the combination by phenotype for Staph. aureus and CNS (Figures 3B and 4B) illustrates the potency of penicillin as the active agent of the combination against penicillin-susceptible staphylococcal isolates and the potency of framycetin 


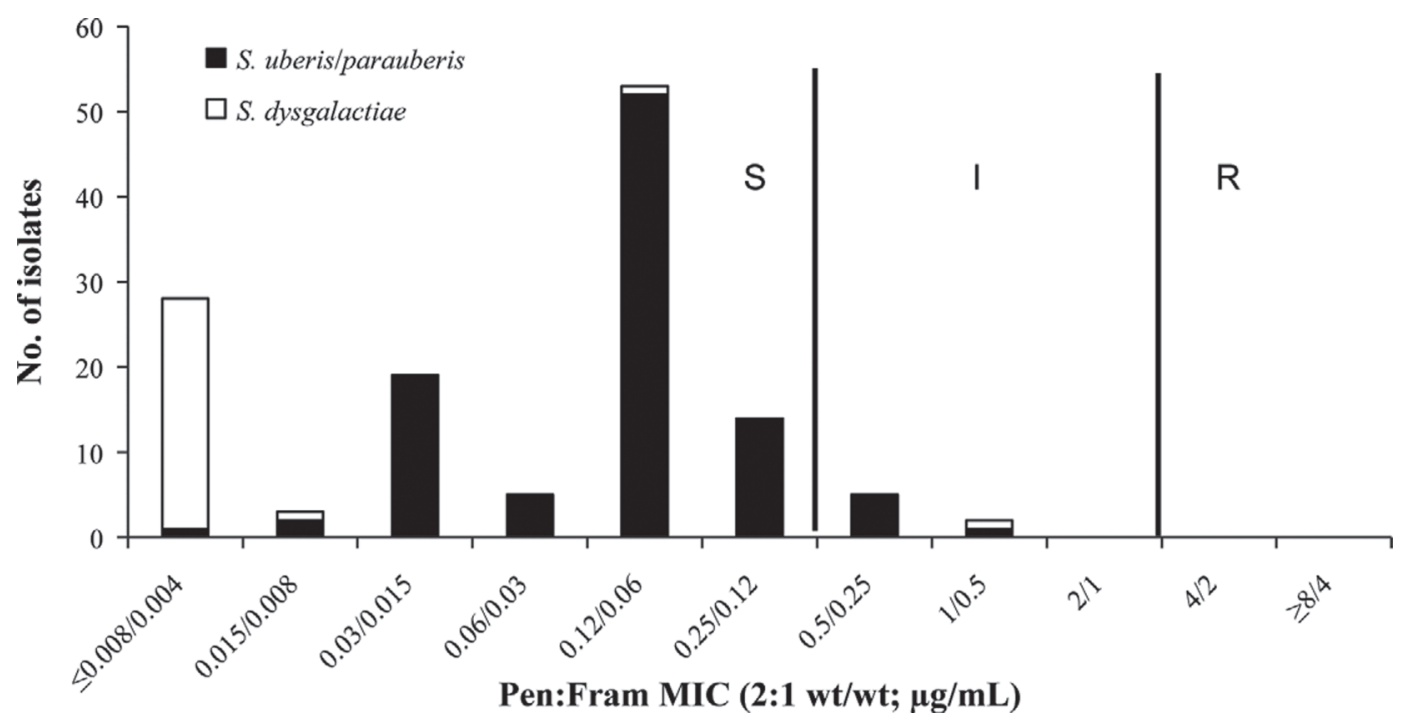

Figure 5. Minimum inhibitory concentration distribution of penicillin:framycetin (Pen:Fram; 2:1 fixed ratio) against veterinary field isolates of Streptococcus uberis or Streptococcus parauberis $(\mathrm{n}=2$ for Strep. parauberis, $\mathrm{n}=97$ for Strep. uberis) and Streptococcus dysgalactiae ( $\mathrm{n}=30$ ). $\mathrm{S}=$ susceptible; $\mathrm{I}=$ intermediate; $\mathrm{R}=$ resistant.

as the active agent of the combination against the penicillin-resistant, kanamycin-susceptible population of staphylococci. For Staph. aureus, framycetin alone typically had MIC values of 0.25 to $2 \mu \mathrm{g} / \mathrm{mL}$ against penicillin-resistant or kanamycin-susceptible isolates, accounting for the observed activity of the combination. For CNS, framycetin alone typically exhibited potent MIC values of $\leq 0.25 \mu \mathrm{g} / \mathrm{mL}$. Preselected penicillin- and kanamycin-resistant human isolates of Staph. aureus were largely resistant to the combination with MIC values of $\geq 16 / 8$ for Staph. aureus, excluding 2 isolates where framycetin alone remained active with MIC values of 1 and $2 \mu \mathrm{g} / \mathrm{mL}$, resulting in MIC values of $1 / 0.5 \mu \mathrm{g} / \mathrm{mL}$ for the combination (Figure 3B).

Notably, for the 2 isolates of Staph. aureus with an MIC of $16 / 8 \mu \mathrm{g} / \mathrm{mL}$, the MIC of penicillin was $\geq 32$ $\mu \mathrm{g} / \mathrm{mL}$ and the MIC of framycetin was $\geq 16 \mu \mathrm{g} / \mathrm{mL}$, which are both not readily achievable in the udder at $>1 \mathrm{~d}$ postadministration. Therefore, it is appropriate for these isolates to be interpreted as resistant to the combination. In addition, $6 \mathrm{CNS}$ isolates were evaluated that had MIC values for the combination of $4 / 2$ to $8 / 4 \mu \mathrm{g} / \mathrm{mL}$. For 3 of these isolates, framycetin had MIC values of 4 to $8 \mu \mathrm{g} / \mathrm{mL}$, which is readily achieved pharmacokinetically, in contrast to the corresponding penicillin MIC values of 16 to $32 \mu \mathrm{g} / \mathrm{mL}$, concentrations which are only achievable $1 \mathrm{~d}$ postadministration. The remaining 3 isolates had framycetin MIC values of $>32 \mu \mathrm{g} / \mathrm{mL}$, which is not maintained postadministration, and penicillin MIC values of 4 and $8 \mu \mathrm{g} /$ $\mathrm{mL}$, which are more likely to be available 1 to $7 \mathrm{~d}$ postadministration. The interpretive criteria are set to yield a result of intermediate susceptibility for these CNS isolates, which is appropriate given the penicillin concentrations achieved during the early dry period. Overall, the preliminary interpretive criteria set for broth microdilution testing of the combination against Staphylococcus spp. fit the observed MIC distributions dividing isolates likely susceptible to penicillin or framycetin from the penicillin- or kanamycin-resistant population with MIC values $\geq 16 / 8 \mu \mathrm{g} / \mathrm{mL}$ (Figure 3 $\mathrm{A}-\mathrm{B}$ and $4 \mathrm{~A}-\mathrm{B})$ and reflect the pharmacokinetically achievable concentrations of penicillin and framycetin in the udder postadministration (Figure 1).

Based on broth MIC values, veterinary isolates of Strep. dysgalactiae were highly susceptible to penicillin $(93.3 \%)$, the active component of the combination against streptococci, and Strep. uberis and Strep. parauberis were largely susceptible $(58.6 \%)$ or of intermediate susceptibility (40.4\%) to penicillin (Table 2), a pattern similar to that observed in other veterinary surveillance (Guérin-Faublée et al., 2002; Rossitto et al., 2002; Hendriksen et al., 2008; Persson et al., 2011). As expected, virtually no activity was observed with either kanamycin or framycetin against streptococci. The combination was very active against both Strep. uberis and Strep. parauberis $\left(\mathrm{MIC}_{50}\right.$ of $0.12 / 0.06 \mu \mathrm{g} /$ $\mathrm{mL}, \mathrm{MIC}_{90}$ of $0.25 / 0.12 \mu \mathrm{g} / \mathrm{mL}$ ) and Strep. dysgalactiae $\left(\mathrm{MIC}_{50}\right.$ and $\mathrm{MIC}_{90}$ of $\left.0.008 / 0.004 \mu \mathrm{g} / \mathrm{mL}\right)$ with susceptibility rates of 94.5 and $96.7 \%$, respectively. The MIC distribution of the combination against the evaluated streptococci is shown in Figure 5. This distribution illustrates the overall potency of the combination and the enhanced potency of the combination against Strep. 
A

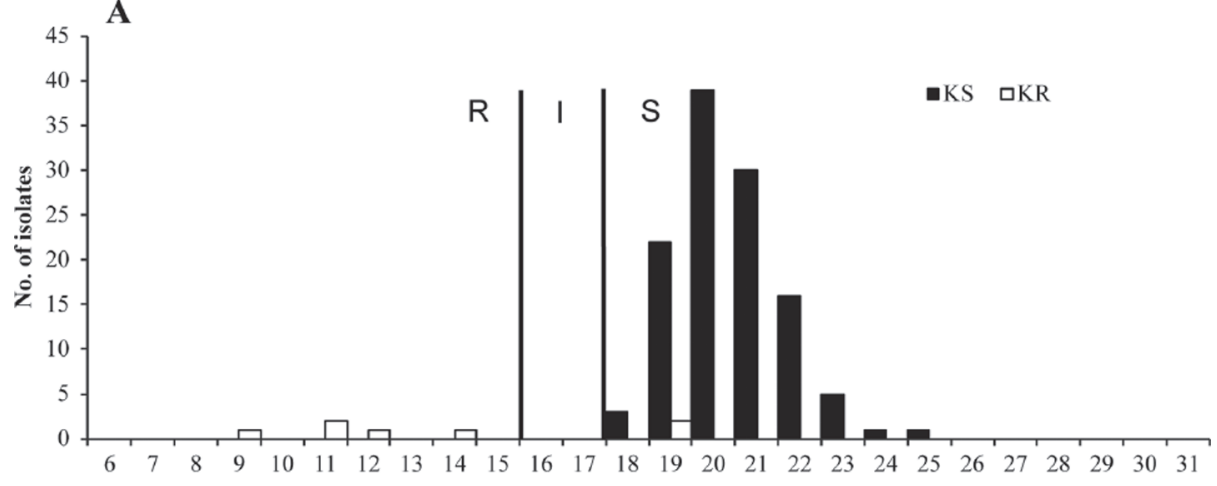

B
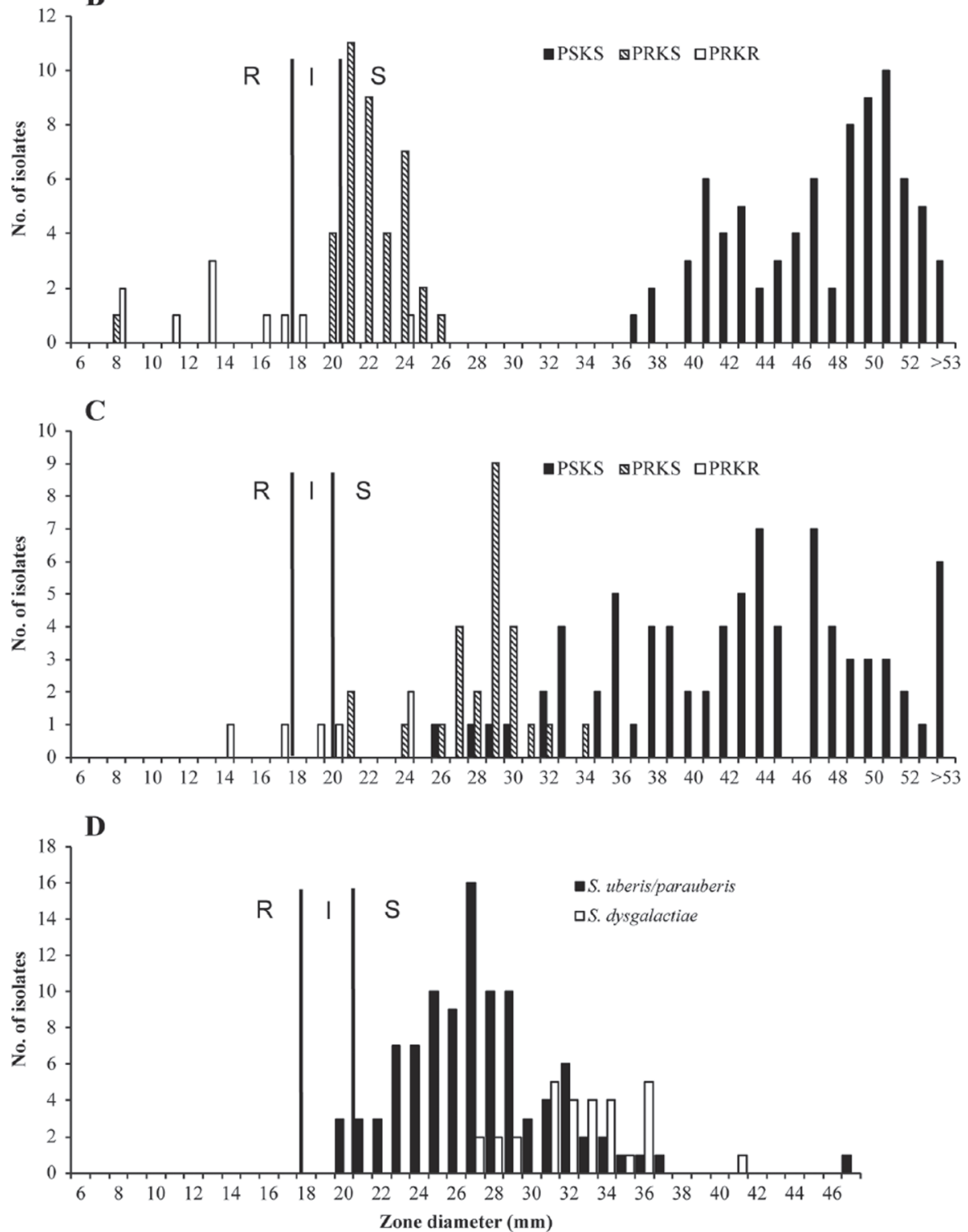

Figure 6. Disk zone distribution of $10 \mathrm{IU}$ of penicillin/100 $\mu \mathrm{g}$ of framycetin disks against the evaluated (A) Escherichia coli $[\mathrm{n}=124$; kanamycin-susceptible $(\mathrm{KS}) \mathrm{n}=117$; kanamycin-resistant $(\mathrm{KR}) \mathrm{n}=7$, (B) Staphylococcus aureus $[\mathrm{n}=128$; penicillin- and kanamycin-susceptible $(\mathrm{PSKS}) \mathrm{n}=79$; penicillin-resistant and kanamycin-susceptible $(\mathrm{PRKS}) \mathrm{n}=39$; penicillin- and kanamycin-resistant $(\mathrm{PRKR}) \mathrm{n}=10],(\mathrm{C}) \mathrm{CNS}$ $(\mathrm{n}=111 ;$ PSKS $\mathrm{n}=79 ;$ PRKS $\mathrm{n}=26$; PRKR $\mathrm{n}=6)$, and $(\mathrm{D})$ streptococci $(\mathrm{n}=128 ;$ Streptococcus uberis $\mathrm{n}=97 ;$ Streptococcus parauberis $\mathrm{n}$ $=2 ;$ Streptococcus dysgalactiae $\mathrm{n}=30$ ). $\mathrm{S}=$ susceptible, $\mathrm{I}=$ intermediate, $\mathrm{R}=$ resistant, $\mathrm{P}=$ penicillin, $\mathrm{K}=$ kanamycin. 
dysgalactiae relative to Strep. uberis and Strep. parauberis, which reflects the variation in potency of penicillin for these species.

Two isolates of Strep. dysgalactiae were nonsusceptible to penicillin with MIC values of 0.25 and $2 \mu \mathrm{g} /$ $\mathrm{mL}$. One isolate of Strep. uberis was penicillin-resistant, with an MIC of $4 \mu \mathrm{g} / \mathrm{mL}$. A large proportion of Strep. uberis were intermediate to penicillin, with MIC values of $0.25-2 \mu \mathrm{g} / \mathrm{mL}$. It is important to note that penicillin MIC results were interpreted using breakpoints relevant for the administration of penicillin at comparatively lower doses in humans relative to the high dose given to dairy cattle as DCT, and as such may not be an accurate reflection of penicillin susceptibility in the context of DCT. Against the isolate of Strep. uberis with a penicillin MIC of $4 \mu \mathrm{g} / \mathrm{mL}$, the combination had an MIC of $1 / 0.5 \mu \mathrm{g} / \mathrm{mL}$, and against the 2 penicillinnonsusceptible Strep. dysgalactiae with penicillin MIC values of 0.25 and $2 \mu \mathrm{g} / \mathrm{mL}$, the combination had an MIC of $0.12 / 0.06$ and 1/0.5, respectively. For Strep. uberis of intermediate susceptibility to penicillin, the combination had MIC values of $0.12 / 0.06$ to $0.25 / 0.12$ $\mu \mathrm{g} / \mathrm{mL}$, excluding $12 \%$ of isolates with MIC values of $0.5 / 0.25 \mu \mathrm{g} / \mathrm{mL}$. As shown in Figure 1, penicillin is available at high amounts after administration, with $86 \mu \mathrm{g} / \mathrm{mL}$ on d $1,3.3 \mu \mathrm{g} / \mathrm{mL}$ on d 6 , and $0.5 \mu \mathrm{g} / \mathrm{mL}$ on $\mathrm{d}$ 14. The interpretive criteria set for the combination fit both the MIC distribution for the evaluated streptococci and the penicillin available in the udder during the early dry-off period. A broad intermediate zone was set at $0.5 / 0.25$ to $2 / 1 \mu \mathrm{g} / \mathrm{mL}$ to reflect that these concentrations of penicillin are achieved with this formulation but only during the early dry-off period.

Based on the broth microdilution interpretive criteria set for the mastitis target organisms, as described previously, the performance of the disk diffusion test was evaluated. For E. coli, the distribution of disk zone diameters based on kanamycin resistance phenotype is shown in Figure 6A. From the distribution it is apparent that by the recommended interpretive criteria (Table 1), resistant zones are appropriately distinguished by zone size from susceptible isolates. The 2 kanamycinresistant isolates with susceptible disk zones had MIC values of $8 / 4$ and $4 / 2 \mu \mathrm{g} / \mathrm{mL}$ for the combination, as framycetin remained active against these isolates.

For Staph. aureus and CNS, the distribution of zone diameters based on penicillin or kanamycin resistance phenotypes is shown in Figure 6 B-C. By disk distribution, the population likely to be susceptible to the combination (penicillin- and kanamycin-susceptible isolates and penicillin-resistant and kanamycin-susceptible isolates) was separated from the population likely to be resistant (isolates resistant to penicillin and kanamycin) using the recommended criteria (Table 1). 
Table 4. Error-rate bounding analysis for the disk diffusion testing of bovine mastitis isolates based on the proposed disk interpretive criteria

\begin{tabular}{llrccc}
\hline & & & \multicolumn{3}{c}{ Error rate (\%) } \\
\cline { 3 - 5 } Isolate & MIC range & $\mathrm{N}$ & Very major & Major & Minor \\
\hline Escherichia coli & $\geq \mathrm{I}+2$ & 5 & 0 & NA $^{1}$ & 0 \\
& $\mathrm{I}+1$ to I-1 & 4 & 0 & 0 & 0 \\
Staphylococcus spp. & $\leq \mathrm{I}-2$ & 115 & $\mathrm{NA}$ & 0 & 0 \\
& $\geq \mathrm{I}+2$ & 6 & 0 & $\mathrm{NA}$ & 0 \\
& $\mathrm{I}+1$ to I-1 & 11 & 0 & 0 & 36.3 \\
Streptococcus spp. & $\leq \mathrm{I}-2$ & 222 & $\mathrm{NA}$ & 0.5 & 2.3 \\
& $\geq \mathrm{I}+2$ & 0 & 0 & $\mathrm{NA}$ & 0 \\
& $\mathrm{I}+1$ to I-1 & 21 & 0 & 0 & 38 \\
& $\leq \mathrm{I}-2$ & 108 & $\mathrm{NA}$ & 0 & 2 \\
\hline
\end{tabular}

${ }^{1} \mathrm{NA}=$ not applicable.

For the evaluated streptococci, the distribution of zone diameters are shown in Figure 6D. The enhanced potency of penicillin against Strep. dysgalactiae relative to Strep. uberis and Strep. parauberis observed by broth microdilution is also readily apparent by disk diffusion, and disk zones are largely interpreted as susceptible, reflecting the potency of penicillin against these isolates.

The comparison of resulting antibiograms for the evaluated strains by broth microdilution and disk diffusion is shown in Table 3. From this analysis it is apparent that when using the interpretive criteria provided herein for the interpretation of MIC or disk zone results for the combination, similar results are observed by both methods. This further illustrates that the disk diffusion test is an accurate reflection of the results observed by broth microdilution testing, which serves as the gold standard. The results presented for the comparators, penicillin and kanamycin, also show that the interpretive criteria for these agents by disk are an accurate reflection of the results observed by broth microdilution.

The overall broth versus disk correlation for evaluated isolates is shown in Figure 7. A linear relationship, with a correlation (r) of 0.76, was observed for the isolates collectively. For E. coli, a strong linear correlation was observed when comparing broth MIC versus disk zone $(\mathrm{r}=0.82)$, and error-rate bounding analysis showed no error rates for interpretation by disk diffusion relative to broth microdilution using the interpretive criteria provided (Table 4). As with E. coli, a strong linear correlation $(\mathrm{r}=0.84)$ was observed for broth microdilution MIC values and disk zone diameters when testing the

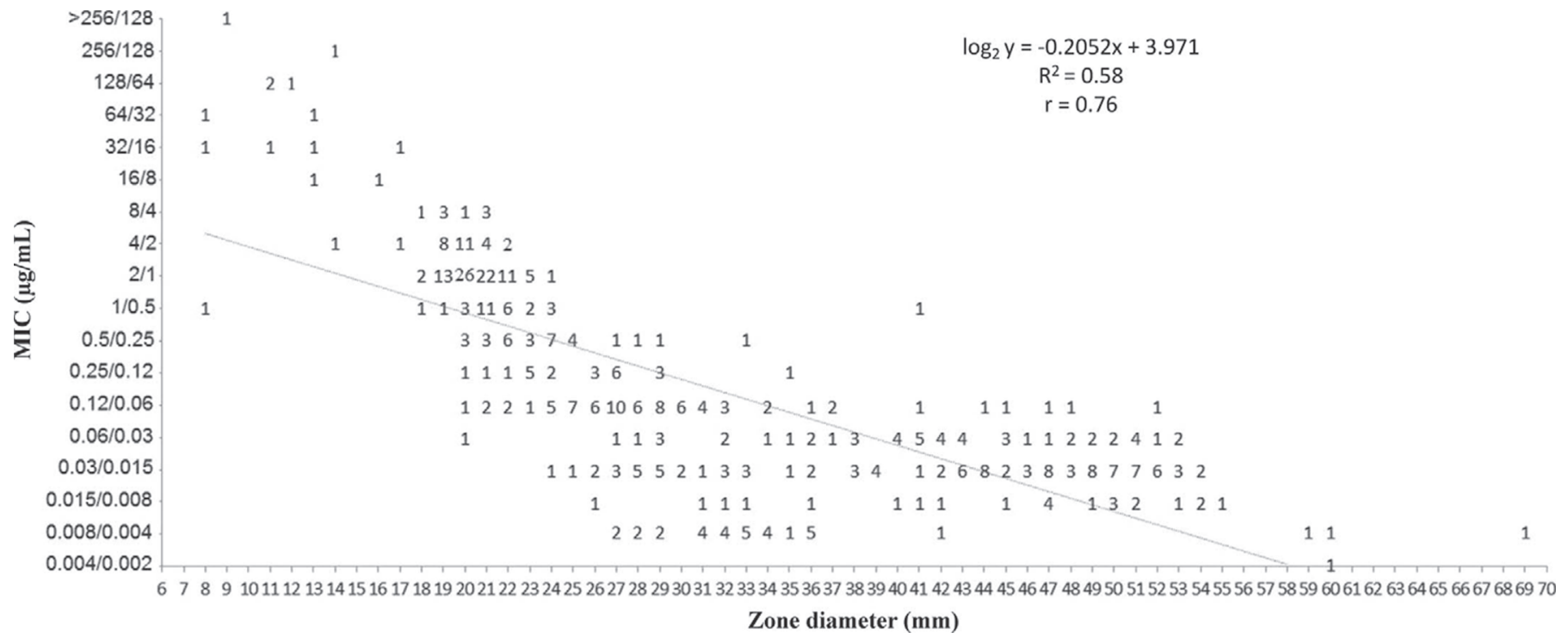

Figure 7. Broth versus disk correlation for penicillin combined with framycetin against evaluated bovine mastitis pathogens $(\mathrm{n}=492$; Escherichia coli $\mathrm{n}=124$, Staphylococcus aureus $\mathrm{n}=128$, CNS $\mathrm{n}=111$, Streptococcus uberis $\mathrm{n}=97$, Streptococcus parauberis $\mathrm{n}=2$, and Streptococcus dysgalactiae $\mathrm{n}=30$ ). 
Table 5. Recommended quality control ranges for the broth microdilution and disk diffusion testing of penicillin in combination with framycetin (2:1 fixed ratio of penicillin:framycetin by broth, $100 \mathrm{of} \mu \mathrm{g}$ framycetin and $10 \mathrm{IU}$ of penicillin $\mathrm{G}$ by disk) against bovine mastitis pathogens

\begin{tabular}{|c|c|c|c|}
\hline Organism & $\begin{array}{l}\text { Zone size } \\
\quad(\mathrm{mm})\end{array}$ & $\begin{array}{c}\mathrm{MIC} \\
(\mu \mathrm{g} / \mathrm{mL})\end{array}$ & $\begin{array}{l}\text { Percent } \\
\text { in range }\end{array}$ \\
\hline Escherichia coli ATCC 25922 & $18-24$ & $1 / 0.5-4 / 2$ & 100 \\
\hline Staphylococcus aureus ATCC 25923 & $27-33$ & $\mathrm{NA}^{2}$ & 100 \\
\hline Staph. aureus ATCC 29213 & NA & $0.25 / 0.12-1 / 0.5$ & 100 \\
\hline Streptococcus pneumoniae ATCC 49619 & $27-33$ & $0.12 / 0.06-0.5 / 0.25$ & 100 \\
\hline
\end{tabular}

${ }^{1}$ Results represent 10 independent inocula tested across three different lots of media $(\mathrm{n}=30)$.

${ }^{2} \mathrm{NA}=$ not applicable.

evaluated staphylococci. As shown in Table 4, using the provided disk interpretive criteria, some minor errors (false intermediate by broth or disk) and one major error (false resistant by disk) were seen, but all error rates were within acceptable limits as established by Clinical and Laboratory Standards Institute (CLSI, 2009a). A low degree of linear correlation $(r=0.43)$ was observed with the evaluated streptococci, which is likely due to the overall susceptibility of the population tested and the lack of resistant isolates from which to judge linearity when testing this species. Nonetheless, as shown in Table 4, despite some minor errors in interpretation by disk relative to broth, no major error or very major error rates were observed when using the recommended criteria by disk.

Finally, as is the case with any antimicrobial agent to be tested regardless of the method, a way for laboratories to perform quality control to ensure that their results are valid needs to be created. This is accomplished by testing standard QC organisms from the ATCC during testing in accordance with Clinical and Laboratory Standards Institute (CLSI, 2009b). In our study, the combination was tested against multiple independent inocula of each relevant ATCC QC organism, with 3 separate lots of test medium. Based on those results, preliminary QC ranges were established for the testing of the combination by broth microdilution and disk diffusion in accordance with Clinical and Laboratory Standards Institute methods (CLSI M31), as described previously (Table 5).

In conclusion, despite the use of penicillin and framycetin in combination as DCT, no method has been defined for in vitro susceptibility testing of this combination. Our study has described the development of methods for testing the combination both by broth microdilution and disk diffusion and corresponding interpretive criteria based on the activity of the combination against a recent representative population of veterinary isolates and the concentrations of the active components after administration. Upon application of these testing methods and interpretive criteria, our study has shown that the combination is active against recent and geographically diverse veterinary mastitis isolates with susceptibility of $98.2,100,96.2,94.5$ and $96.7 \%$ against E. coli, Staph. aureus, CNS, Strep. uberis and Strep. parauberis, and Strep. dysgalactiae, all common pathogens of bovine mastitis. Though these criteria are not clinically predictive, they provide a means by which to monitor the activity of this combination against target mastitis pathogens and to identify any emerging resistance to the combination going forward.

\section{ACKNOWLEDGMENTS}

The authors acknowledge Andrew Bradley and Barbara Payne from Quality Milk Management (Cheddar, UK) for supplying the bovine mastitis field isolates tested in this study. The study was sponsored by Boehringer Ingelheim Animal Health GmbH (Ingelheim, Germany).

\section{REFERENCES}

Aarestrup, F., and S. Schwarz. 2006. Antimicrobial resistance in staphylococci and streptococci of animal origin. Pages 187-212 In Antimicrobial Resistance in Bacteria of Animal Origin. F. Aarestrup, ed. ASM Press, Washington, DC.

Almeida, R. A., D. Patel, G. M. Friton, and S. P. Oliver. 2007. Intracellular killing of mastitis pathogens by penethamate hydriodide followin internalization into mammary epithelial cells. J. Vet. Pharmacol. Ther. 30:151-156.

Berry, E. A., and J. E. Hillerton. 2002. The effect of selective dry cow treatment on new intramammary infections. J. Dairy Sci. $85: 112-121$

Berry, E. A., H. Hogeveen, and J. E. Hillerton. 2004. Decision tree analysis to evaluate dry cow strategies under UK conditions. J. Dairy Res. 71:409-418.

Boehringer Ingelheim. 2013. Ubrostar - Summary of Product Characteristics. Accessed Jan. 17, 2014. http://www.ubrostar. com/content/dam/internet/ah/ubrostar/com_EN/documents/ SPC.pdf.

Bradley, A. 2002. Bovine mastitis: An evolving disease. Vet. J. 164:116-128.

Bradley, A. J., and M. J. Green. 2001. An investigation of the impact of intramammary antibiotic dry cow therapy on clinical coliform mastitis. J. Dairy Sci. 84:1632-1639.

Bradley, A. J., and M. J. Green. 2004. The importance of the nonlactating period in the epidemiology of intramammary infection and strategies for prevention. Vet. Clin. North Am. Food Anim. Pract. 20:547-568 
Bradley, A. J., and M. J. Green. 2009. Factors affecting cure when treating bovine clinical mastitis with cephalosporin-based intramammary preparations. J. Dairy Sci. 92:1941-1953.

CLSI. 2009a. Development of In Vitro Susceptibility Testing Criteria and Quality Control Parameters for Veterinary Antimicrobial Agents; Approved Guideline (document M37-A3). 3rd ed. Clinical and Laboratory Standards Institute (CLSI), Wayne, PA.

CLSI. 2009b. Methods for Antimicrobial Disk and Dilution Susceptibility Tests for Bacteria Isolated from Animals; Approved Standard (document M31-A3). 3rd ed. Clinical and Laboratory Standards Institute (CLSI), Wayne, PA.

El Behiry, A., G. Schlenker, I. Szabo, and U. Roesler. In vitro susceptibility of Staphylococcus aureus strains isolated from cows with subclinical mastitis to different antimicrobial agents. J. Vet. Sci. 13:153-161.

EMEA (European Agency for the Evaluation of Medicinal Products). 2002. Committee for Veterinary Medicinal Products. Neomycin Summary Report. EMEA/MRL/816/02-Final. January 2002. European Medicines Agency (EMA), London, UK.

Ericsson Unnerstad, H., A. Lindberg, K. Persson Waller, T. Ekman, K. Artursson, N. Nilsson-O, and B. Bengtsson. 2009. Microbial aetiology of acute clinical mastitis and agent-specific risk factors. Vet. Microbiol. 137:90-97.

Erskine, R. J., R. D. Walker, C. A. Bolin, P. C. Bartlett, and D. G. White. 2002. Trends in antibacterial susceptibility of mastitis pathogens during a seven-year period. J. Dairy Sci. 85:1111-1118.

Fitzpatrick, J. L., F. J. Young, D. Eckersall, D. N. Logue, C. J. Knight, and A. Nolan. 1998. Recognising and controlling pain and inflammation in mastitis. Proceedings of the British Mastitis Conference 36-44. The Dairy Group, University of Nottingham, Nottingham, UK.

Friton, G., J. J. C. van Hattum, and D. Hörstermann. 2003. Pharmacokinetics in plasma and milk of benzylpenicillin following repeated intramuscular administration of Mamyzin (penethamate hydriodide) in lactating cows. J. Vet. Pharmacol. Ther. 26(Suppl. 1):100-101.

Gentilini, E., G. Denamiel, P. Llorente, S. Godaly, M. Rebuelto, and O. DeGregorio. 2000. Antimicrobial susceptibility of Staphylococcus aureus isolated from bovine mastitis in Argentina. J. Dairy Sci. 83:1224-1227.

Guérin-Faublée, V., F. Tardy, C. Bouveron, and G. Carret. 2002. Antimicrobial susceptibility of Streptococcus species isolated from clinical mastitis in dairy cows. Int. J. Antimicrob. Agents 19:219-226.

Hendriksen, R. S., D. J. Mevius, A. Schroeter, C. Teale, D. Meunier, P. Butaye, A. Franco, A. Utinane, A. Amado, M. Moreno, C. Greko, K. Stark, C. Berghold, A. L. Myllyniemi, D. Wasyl, M. Sunde, and F. M. Aarestrup. 2008. Prevalence of antimicrobial resistance among bacterial pathogens isolated from cattle in different European countries: 2002-2004. Acta Vet. Scand. 50:28.

Hillerton, J. E., and E. A. Berry. 2005. Treating mastitis in the cowA tradition or an archaism. J. Appl. Microbiol. 98:1250-1255.

Hogeveen, H., S. Pyörälä, K. Persson Waller, J. S. Hogan, T. J. G. M. Lam, S. P. Oliver, Y. H. Schukken, H. W. Barkema, and J. E. Hillerton. 2011. Current status and future challenges in mastitis research. NMC Annual Meeting Proceedings 36-48. National Mastitis Council, Arlington, VA.

Lehtolainen, T., A. Shwimmer, N. Y. Shpigel, T. Honkanen-Buzalski, and S. Pyörälä. 2003. In vitro antimicrobial susceptibility of Escherichia coli isolates from clinical bovine mastitis in Finland and Israel. J. Dairy Sci. 86:3927-3932.
Makovec, J. A., and P. L. Ruegg. 2003. Antimicrobial resistance of bacteria isolated from dairy cow milk samples submitted for bacterial culture: 8,905 samples (1994-2001). J. Am. Vet. Med. Assoc. 222:1582-1589.

National Mastitis Council. 2006. Dry Cow Therapy. Accessed Jan. 27, 2014. http://nmconline.org/drycow.htm

Oliveira, L., H. Langoni, C. Hulland, and P. L. Ruegg. 2012. Minimum inhibitory concentrations of Staphylococcus aureus recovered from clinical and subclinical cases of bovine mastitis. J. Dairy Sci. 95:1913-1920.

Osterås, O., J. Aursjo, G. G. Gronningsaeter, and A. Jorstad. 1994. Effect of dry-cow therapy on subclinical mastitis-An evaluation of long-acting and short-acting intramammaria. Zentralbl. Veterinarmed. B 41:529-540.

Osterås, O., and L. Sandvik. 1996. Effects of selective dry-cow therapy on culling rate, clinical mastitis, milk yield and cow somatic cell count. A randomized clinical field study in cows. Zentralbl. Veterinarmed. B 43:555-575.

Persson, Y., A. K. Nyman, and U. Gronlund-Andersson. 2011. Etiology and antimicrobial susceptibility of udder pathogens from cases of subclinical mastitis in dairy cows in Sweden. Acta. Vet. Scand. $53: 36$.

Pillar, C. M., L. Goby, D. Draghi, P. Grover, and C. Thornsberry 2009. Evaluating the in vitro susceptibility of bovine mastitis pathogens to a combination of kanamycin and cefalexin: Recommendations for a disk diffusion test. J. Dairy Sci. 92:6217-6227.

Pitkälä, A., M. Haveri, S. Pyörälä, V. Myllys, and T. Honkanen-Buzalski. 2004. Bovine mastitis in Finland 2001-Prevalence, distribution of bacteria, and antimicrobial resistance. J. Dairy Sci. 87:2433-2441.

Pyörälä, S., and S. Taponen., 2009. Coagulase-negative staphylococci: Emerging mastitis pathogens. Vet Microbiol. 134:3-8.

Rossitto, P. V., L. Ruiz, Y. Kikuchi, K. Glenn, K. Luiz, J. L. Watts, and J. S. Cullor. 2002. Antibiotic susceptibility patterns for environmental streptococci isolated from bovine mastitis in central California dairies. J. Dairy Sci. 85:132-138.

Silley, P., L. Goby, and C. M. Pillar. 2012. Susceptibility of coagulasenegative staphylococci to a kanamycin and cefalexin combination. J. Dairy Sci. 95:3448-3453.

Smith, A., D. R. Westgarth, M. R. Jones, F. K. Neave, F. H. Dodd, and G. C. Brander. 1967. Methods of reducing the incidence of udder infection in dry cows. Vet. Rec. 81:504-510.

Ungemach, F. R., D. Müller-Bahrdt, and G. Abraham. 2006. Guidelines for prudent use of antimicrobials and their implications on antibiotic usage in veterinary medicine. Int. J. Med. Microbiol. 296(Suppl. 41):33-38.

Wallmann, J., K. Schroter, L. H. Wieler, and R. Kroker. 2003. National antibiotic resistance monitoring in veterinary pathogens from sick food-producing animals: The German programme and results from the 2001 pilot study. Int. J. Antimicrob. Agents 22:420-428.

Watts, J. L. 1988. Etiological agents of bovine mastitis. Vet. Microbiol. 16:41-66.

White, D. G. 2006. Antimicrobial resistance in pathogenic Escherichia coli from animals. Pages 145-166 in Antimicrobial Resistance in Bacteria of Animal Origin. F. Aarestrup, ed. ASM Press, Washington, DC

Ziv, G. 1980. Practical pharmacokinetic aspects of mastitis therapy - 3: Intramammary treatment. Vet. Med. Small Anim. Clin. 75:657-670. 